\title{
Continuing Care between Hospital and Home about Percutaneous Endoscopic Gastrostomy Based on the Experience of Patients with Amyotrophic Lateral Sclerosis
}

\author{
Mitsuko Ushikubo, ${ }^{1}$ Mina Kanbe, ${ }^{2}$ Mieko Sukawa, ${ }^{3}$ \\ Chieko Tomita $^{3}$ and Sachiyo Hoshikawa ${ }^{3}$
}

\begin{abstract}
Aims : The purpose of this study was to elucidate experiences of ALS patients who had undergone percutaneous endoscopic gastrostomy (PEG) placement and their families in relation to the gastrostomy and find the continuing care between the hospital and community. Methods: Semi-structured interviews were conducted with six amyotrophic lateral sclerosis (ALS) patients who underwent gastrostomy to elaborate on their experiences with PEG at the hospital and leading to their discharge. Results : There were changes for more positive attitudes in accepting PEG. The following were cited as the major reasons for such changes: (1) Switch to more appropriate gastrostomy tube; (2) Improvement in the troublesome aspects; and (3) Realization of the need for the PEG. On the other hand, the following were extracted as the troublesome experiences related to the procedure: [skin trouble], [leakage of nutrition formula], [malfunctioning of the equipment], [difficulties with self care] and [insufficient information], etc. Conclusions : It is considered necessary to select appropriate types of gastrostomy tube and offer adequate guidance through the cooperation of multiple disciplines in and out of the hospital. Health professions need to prepare for changes of physical function in daily activities associated with exacerbation of the disease so that ALS patients may have an adequate understanding of the procedure and be capable of accepting continuing care. (Kitakanto Med J $2010 ; 60: 135 \sim 141$ )
\end{abstract}

Key Words : ALS, nanbyo, PEG, continuing care, home care

\section{Introduction}

Amyotrophic lateral sclerosis (ALS) is a progressive neuromuscular disorder that inevitable fatal with an average life expectancy of two or five years. ${ }^{1} \quad$ ALS is characterized by a progressive loss of muscle strength resulting in loss of functional activities. The associated physical disability is progressive and affects limb movements, speech, swallowing and respiration that inexorably result in death.

There are no effective treatments to stop or reverse the natural course of the disease. Therefore, the mainstay of treatment consists of symptomatic management: use of non-invasive ventilator, use of mechanical ventilation, tracheotomy, percutaneous endoscopic gastrostomy (PEG) tube placement, and/or communi- cation devices. ${ }^{2}$

As the nourishment is an important component in the disease management and caring for $\mathrm{ALS},{ }^{3}$ this study focused PEG among these medical treatments. Because of the risk of surgery in patients with reduced respiratory function ${ }^{4}$ and the expectation of a lifeprolonging effect, ${ }^{5}$ early PEG is recommended in patients with ALS. ${ }^{6,7}$ PEG reduces the physical exhaustion that results from the longer time required for oral feeding and the risk of aspiration, and it also makes it possible to easily maintain and improve nutritional status.

Because of the ease of placing a PEG and the convenience of management, increases in the number of operations have been seen among cancer patients and patients with neurological disease. ${ }^{8,9}$ Meanwhile,

1 School of Health Sciences, Gunma University Faculty of Medicine, 3-39-22 Showa-machi, Maebashi, Gunma 371-8511,

Japan 2 Department of Nursing, Municipal Nanokaichi Hospital, 643 Nanokaichi, Tomioka, Gunma 370-2343, Japan

3 Department of Nursing, Gunma University Hospital, 3-39-15 Showa-machi, Maebashi, Gunma 371-8511, Japan

Received: February 22, 2010

Address: MITSUKO USHIKUBO School of Health Sciences, Gunma University Faculty of Medicine, 3-39-22 Showamachi, Maebashi, Gunma 371-8511, Japan 
there are quite a few complications, and after discharge from the hospital, cases in which skin trouble develops around the stoma or cases in which replacement management is neglected are not uncommon. ${ }^{3}$ Education of patients and their families with a view to life after discharge from the hospital is necessary so that ALS patients with deteriorating condition will perform care of the stoma tract as part of their own body. In cases where patients' capacity for self care and the nursing care ability of the family is limited, it is necessary to work together with clinic or visiting nursing station.

The purpose of this study was to elucidate experiences of ALS patients who had undergone PEG placement and their families in relation to the gastrostomy, and in view of the current circumstances in which the site of treatment is increasingly shifting to the home, to assess the optimal approach to discharge education that emphasizes self care and the optimal approach to continuous care with the hospital and community.

\section{Methods}

\section{Participants}

The participants in this study were: 1) patients who were admitted to hospital A for the purpose of undergoing PEG and were scheduled for home care after discharge and their families (new-gastrostomy participants), and 2) patients who had already undergone PEG at hospital A three to 12 months before and their families (existing-gastrostomy participants), who gave their consent to participate in this study. Those with an existing gastrostomy described in 2) above were included in the study because of the difficulty of securing the planned number of subjects of the study during the conduct of the survey.

\section{Procedure}

1. Survey methods used in both the new-gastrostomy group and the existing-gastrostomy group

1) Medical record review survey

Survey items: Patients' basic information (diagnosis, age, gender, time of onset, past medical history, history of the present illness, family composition, main family caregiver conditions), whether utilizing public resources, conditions from admission to discharge, and nature of the medical care and nursing care provided.

2 ) Interview survey after discharge

Survey items: Conditions after discharge, acceptance of the stoma, problems with stoma care, trouble experienced, etc.

Survey methods: A semi-structured interview survey of participants with a new gastrostomy was conducted during the first clinic visit after discharge or during a visit to the patient's home approximately two weeks to one month after discharge. A semi-structured interview survey of participants with an existing gastrostomy was conducted during a clinic visit or a visit to the patient's home.

2. Survey during the hospital stay of only the new-gastrostomy group

Survey items :

\{Before surgery\} Acceptance of the gastrostomy

\{Between 2-3 days after the gastrostomy procedure and the day of discharge $\}$

Content of the instructions received in regard to the stoma (e.g., management, skin care, a method of infusing the nutrient formula) and the level of understanding, problems, acceptance of the gastrostomy, etc.

Survey methods: Performed by participantobservation and by semi-structured interview of the patient and family.

\section{Methods of analysis}

We used the qualitative induction analysis method. The category and the subcategory were extracted about data concerning 'trouble', 'improper understanding', and 'content of caring'. It examined among co-investigators to secure trustworthiness in the analysis process.

\section{Ethical consideration}

The study was approved by the institutional review board of Gunma University. Signed consent was obtained from the subjects after explaining both verbally and in writing the purpose and method of this study, freedom to decline participation, and so on.

\section{Results}

\section{Sample description (Table 1)}

The sample consisted of three patients with an existing gastrostomy, each with at least one family member, and three patients with a new gastrostomy, each with at least one family member. All of the patients with an existing gastrostomy had experience with replacement. Their ages were in the 6th and 7th decade of life. At the time of the survey four patients were on noninvasive positive-pressure ventilation (NPPV), and the conversation with two of them was in writing. Stoma care was provided by various people, including patients themselves, their family, and both of the family and a visiting nurse. Three patients began using their gastrostomy tube immediately after placement.

Changes in acceptance of the gastrostomy (Table 2)

Among the participants with an existing gastrostomy, positive changes in emotion were seen from 
Table 1 Description of participants

\begin{tabular}{|c|c|c|c|c|c|c|}
\hline \multirow{2}{*}{ Case } & \multicolumn{3}{|c|}{ Patient with existing gastrostomy } & \multicolumn{3}{|c|}{ Patient with a new gastrostomy } \\
\hline & A & B & $\mathrm{C}$ & $\mathrm{D}$ & $\mathrm{E}$ & $\mathrm{F}$ \\
\hline age & $\begin{array}{l}\text { in 1st half of } \\
\text { the sixties }\end{array}$ & $\begin{array}{l}\text { in 1st half of } \\
\text { the sixties }\end{array}$ & $\begin{array}{l}\text { in } 2 \text { nd half of } \\
\text { the sixties }\end{array}$ & $\begin{array}{l}\text { in } 2 \text { nd half of } \\
\text { the fifties }\end{array}$ & $\begin{array}{l}\text { in 1st half of } \\
\text { the sixties }\end{array}$ & $\begin{array}{l}\text { in 1st half of } \\
\text { the sixties }\end{array}$ \\
\hline commobidity & $(-)$ & $(一)$ & $(一)$ & heart disease & stomach cancer & $(-)$ \\
\hline $\begin{array}{l}\text { family living } \\
\text { together }\end{array}$ & daughter's family & husband & wife & wife & wife & husband \\
\hline care provider & $\begin{array}{c}\text { daughter and home } \\
\text { care nurse }\end{array}$ & patient & from patient to wife & wife & patient & husband \\
\hline $\begin{array}{l}\text { other medical } \\
\text { treatments }\end{array}$ & \multicolumn{3}{|c|}{ NPPV } & NPPV & $(-)$ & $(-)$ \\
\hline $\begin{array}{c}\text { verbal } \\
\text { communication }\end{array}$ & possible & in writing & possible & possible & in writing & possible \\
\hline Kind of tube & \multicolumn{3}{|c|}{ bumber and tube type $\rightarrow$ button type } & \multirow{2}{*}{\multicolumn{3}{|c|}{ bumber and button type }} \\
\hline $\begin{array}{l}\text { period after } \\
\text { placement }\end{array}$ & 6 months & 4 months & $1 \mathrm{yr}$ and $1 \mathrm{mo}$. & & & \\
\hline ways of feeding & by oral & oral and PEG & PEG & oral and PEG & PEG & oral \\
\hline interviewees & $\begin{array}{l}\text { patient and } \\
\text { her daughter }\end{array}$ & patient & patient and his wife & patient and his wife & patient & patient \\
\hline
\end{tabular}

NPPV stands for noninvasive positive-pressure ventilation. PEG stands for percutaneous endoscopic gastrostomy.

"There's no other choice" and "It's unavoidable" before the operation, to "I'm glad I had it done" and "The gastrostomy is great" after the operation. On the other hand, the daughter of patient A, who was capable of oral feeding at the time of survey, said that she harbored doubts about the need for the gastrostomy.

Among the participants with a new gastrostomy, positive acceptance was heard from patient E and patient $\mathrm{F}$, in whom nutrition via the gastrostomy tube was started shortly after surgery, but it was impossible to obtain any answers related to the gastrostomy from patient $\mathrm{D}$ because of his unstable neurological status as a result of repeated worsening of his condition soon after the diagnosis, and because of postoperative pain. However, infusion of a nutrient formula via the gastrostomy tube became necessary three weeks after discharge from the hospital because sufficient nutrition was no longer taken by oral feeding alone, and patient D's wife made the positive statement, "I'm glad he had it done ahead of time; he's able to be nourished".

\section{Experienced trouble (Table 3)}

[ ] denotes a category, \langle\rangle a subcategory and “ " a concrete content.

[Diarrhea] was identified as trouble during the hospital stay, and [insufficient information], such as, "the visiting nurses taught me everything", was identified during the transition to home since little information was provided by the hospital in regard to care. [Skin trouble], [leakage of the nutrient formula], [malfunctioning of the equipment], [difficulty with self care], and [others] were identified as trouble during home care. Trouble identified in relation to gastrostomy replacement included: [pain and accidents associated with the replacement procedure], including "It hurt", "it was jammed in", "I developed severe dermatitis caused by the replacement procedure and required emergency admission to the hospital"; [complaints/ dissatisfaction with the gastrostomy after replacement], saying that the type or size of the gastrostomy was changed against their will; and [complaints/dissatisfaction with the response of the medical staff], such as having to wait a long time after administration of the anesthesia.

\section{Inappropriate understanding and content of care}

As shown in Table 4, during the participantobservation in the hospital or during the interview in the hospital or at home, the main inappropriate understandings or nature of care were: [inadequate awareness of care of the insertion site], such as "Is it all right to touch the gastrostomy site?", "misunderstanding of the need to rotate the gastrostomy tube once a day", and "I didn't know about twisting the tissue paper"; [inappropriate care of the insertion site] such as 〈unnecessary Y-cut gauze attachment〉, 〈unnecessary application of ointment $\rangle$, 〈neglecting a tight bumper attachment ; [inadequate recognition of gastrostomy management from an everyday living standpoint], such as "I didn't know whether it would be all right to infuse other things besides the nutrient formula"; and [ignorance of the time for replacement].

Demands and hopes from the standpoint of those who had undergone gastrostomy

Wishes were identified for "the development of a 
Table 2 Changes in acceptance of the gastrostomy

\begin{tabular}{|c|c|c|c|}
\hline Participants & before gastrostomy & after gastrostomy & How to change \\
\hline \multicolumn{4}{|c|}{ 【Patients with an exising- gastorstomy】 } \\
\hline Patient A & - It was safe for me to place PEG ahead of time. & $\begin{array}{l}\text {-I don't care as it is like an accessory now. } \\
\text { - I need it if anything happens to me. }\end{array}$ & positive $\rightarrow$ positive \\
\hline Patient B & $\begin{array}{l}\text {-It was unavoidable because my doctor recom- } \\
\text { mended it as early as I can have endoscopy. }\end{array}$ & $\begin{array}{l}\text { - A } 30 \mathrm{~cm} \text { long tube was troublesome to me in the } \\
\text { daily life and I can't take a public bath because } \\
\text { everybody can notice my PEG tube. } \\
\text { - My PEG tube was changed to a button type. } \\
\text { The PEG is great because of a convenient way } \\
\text { to take nutrition easily. } \\
\text { - I was exhausted to eat and take a long time. } \\
\text { So, I am satisfied with infusion by PEG. }\end{array}$ & $\begin{array}{l}\text { negative } \rightarrow \text { positive } \\
\text { (after the replacement) }\end{array}$ \\
\hline Patient C & $\begin{array}{l}\text {-I didn't expect to place PEG. } \\
\text { - There was no other choice because I felt diffi- } \\
\text { culty with oral feedings. }\end{array}$ & $\begin{array}{l}\text {-I felt a pain in granulation tissue after hospital } \\
\text { discharge. } \\
\text { I am glad I had it done. }\end{array}$ & $\begin{array}{l}\quad \text { negative } \rightarrow \text { positive } \\
\text { (after improvement of abnormal } \\
\text { granulation tissues) }\end{array}$ \\
\hline $\begin{array}{l}\text { Family C } \\
\text { (wife) }\end{array}$ & $\begin{array}{l}\text { - The doctor told to only me that he wound die } \\
\text { if he didn't place PEG as soon as possible. So, } \\
\text { I had no choice. He must make it. }\end{array}$ & $\begin{array}{l}\text {-It was a correct choice, otherwise he would } \\
\text { already have passed away. }\end{array}$ & positive $\rightarrow$ positive \\
\hline $\begin{array}{l}\text { Family A } \\
\text { (daughter) }\end{array}$ & $\begin{array}{l}\text {-I thought she had better to place PEG, because } \\
\text { I thought her symptom would aggravate as a } \\
\text { burst. }\end{array}$ & $\begin{array}{l}\text { - As she can still eat by her mouth, I am wonder- } \\
\text { ing if she needs PEG placement or not. }\end{array}$ & $\begin{array}{l}\text { positive } \rightarrow \text { doubts about the } \\
\text { need for the gastrostomy }\end{array}$ \\
\hline \multicolumn{4}{|c|}{ 【Patients with a new-gastrostomy】 } \\
\hline Patient E & $\begin{array}{l}\text { - It was unavoidable because I was not able to } \\
\text { eat. }\end{array}$ & $\begin{array}{l}\text { - I am not worried about the nutrition any more. } \\
\text { - It is good that the diarrhea has stopped. }\end{array}$ & negative $\rightarrow$ positive \\
\hline Patient F & - It had better for me to place PEG for the future. & $\begin{array}{l}\text { - PEG put my mind at ease, because I can take } \\
\text { nutrition easily. }\end{array}$ & positive $\rightarrow$ positive \\
\hline
\end{tabular}

PEG stands for percutaneous endoscopic gastrostomy.

Table 3 Experienced trouble

\begin{tabular}{|c|c|c|}
\hline timeline & Category & Subcategory \\
\hline hospital stay & 【diarrhea】 & $\langle$ diarrhea $\rangle$ \\
\hline $\begin{array}{l}\text { during transition } \\
\text { to home }\end{array}$ & 【insufficient information】 & $\begin{array}{l}\langle\text { insufficient information about how to obtain necessities }\rangle \\
\langle\text { missing passing of nutrition tube }\rangle \\
\langle\text { missing passing of the accompaniments }\rangle \\
\langle\text { insufficient explainment about time of replacement }\rangle \\
\langle\text { little information provided by hospital }\rangle\end{array}$ \\
\hline \multirow{5}{*}{ during home care } & 【skin trouble】 & $\begin{array}{l}\langle\text { blush of skin surrounding stoma }\rangle \\
\langle\text { abnormal granulation }\rangle \\
\langle\text { hemorrhage }\rangle \\
\langle\text { stinking }\rangle\end{array}$ \\
\hline & 【leakage of nutrition formula】 & $\begin{array}{l}\langle\text { leakage of the injected nutrition from tube insertion }\rangle \\
\langle\text { leakage because of loosening cap }\rangle\end{array}$ \\
\hline & 【malfunctioning of the equipment】 & $\begin{array}{l}\langle\text { I was trouble when I wanted to go to toilet during injected because the drip } \\
\text { stand didn't move. } \\
\langle\text { loosening of the cap of PEG tube }\rangle\end{array}$ \\
\hline & 【difficulty with self care】 & $\begin{array}{l}\langle\mathrm{I} \text { am no longer able to take care of myself, because my hands were getting } \\
\text { not to work } \\
\langle\mathrm{I} \text { can no longer pull the shirt off, because my hands were getting not to } \\
\text { work. } \\
\langle\mathrm{I} \text { would take care of it by myself if the type of PEG tube was the same as the } \\
\text { previous one. }\end{array}$ \\
\hline & 【others】 & $\begin{array}{l}\text { 〈I cannot contain myself when nutrition is injected because somebody come, } \\
\text { I drop something, and so on〉 }\end{array}$ \\
\hline \multirow{3}{*}{$\begin{array}{l}\text { during hospital stay } \\
\text { for PEG replacement }\end{array}$} & $\begin{array}{l}\text { 【pain and accident associated with the } \\
\text { replacement procedurel】 }\end{array}$ & $\begin{array}{l}\langle\text { suffered pain accompanied with replacement procedure }\rangle \\
\langle\mathrm{I} \text { had severe dermatitis caused by the replacement and required emergency } \\
\text { admission to the hospital }\rangle\end{array}$ \\
\hline & $\begin{array}{l}\text { 【complainments/dissatisfaction with gas- } \\
\text { trostomy replacement】 }\end{array}$ & $\begin{array}{l}\langle\text { change to unwilling type }\rangle \\
\langle\text { improper size }\rangle\end{array}$ \\
\hline & $\begin{array}{l}\text { 【complaints/dissatisfaction with the } \\
\text { response of the medical staff】 }\end{array}$ & $\langle$ having to wait a long time after administration of the anesthesia $\rangle$ \\
\hline
\end{tabular}

PEG stands for percutaneous endoscopic gastrostomy. 
Table 4 Inappropriate understandings and content of care

\begin{tabular}{|c|c|c|}
\hline theme & category & "concrete remarks" and \\
\hline \multirow[t]{2}{*}{$\begin{array}{l}\text { care of the insertion } \\
\text { site }\end{array}$} & $\begin{array}{l}\text { 【inadequate awareness of care of the inser- } \\
\text { tion site】 }\end{array}$ & $\begin{array}{l}\text { "Is it all right to touch the gastrostomy site?" } \\
\text { 〈misunderstanding of the need to rotate the gastrostomy tube once a day } \\
\text { "I understand that ointment of gentamaicin sulfate can stop bleeding around } \\
\text { PEG fistula." } \\
\text { "I didn't know about twisting the tissue." }\end{array}$ \\
\hline & 【inappropriate care of the insertion site】 & $\begin{array}{l}\langle\text { unnecessary Y-cut gauze attachment〉 } \\
\text { "A gauze was applied to the PEG insertion and nobody gave skin care until } \\
\text { the doctor removed the stitchces." } \\
\langle\text { unnecessary application of ointment }\rangle \\
\langle\text { neglecting a tight bumper attachment }\rangle\end{array}$ \\
\hline daily life & $\begin{array}{l}\text { 【inadequate recognition of gastrostomy } \\
\text { management from a every living standpoint】 }\end{array}$ & $\begin{array}{l}\text { "I didn't know whether it would be all right to infuse other things besides the } \\
\text { nutrient fomula." } \\
\text { "I worried about whether tea I swallowed discharged from the PEG fistula." } \\
\text { "I worried that the hot water comes in from the PEG fistula when I take a } \\
\text { shower or a bath." }\end{array}$ \\
\hline replacement & 【ignorance of the time for replacement】 & "I didn't know the time for replacement." \\
\hline disinfection & 【inappropriate way to disinfect】 & $\begin{array}{l}\langle\text { The nurse went PEG tube soaked in antiseptic solution for quite a long } \\
\text { time. } \\
\langle\text { The nurse soaked the PEG tube in undiluted antiseptic solution. }\rangle\end{array}$ \\
\hline
\end{tabular}

PEG stands for percutaneous endoscopic gastrostomy.

two or three times higher calorie nutrient formula" so that patients could always obtain the calories needed even with the small volume when their condition was poor, "smooth collaboration in the hospital (surgery department and neurology department)" seeking seamless medical care when the attending physician and the surgeon were different, and "improvement in the replacement procedure" so that there would be no pain or accidents during replacement.

\section{Discussion}

Patients described a variety of experiences during their hospital stay and their subsequent home care. We will discuss continuing care in regard to the PEG management of ALS patients based on these experiences.

\section{Support to obtain positive acceptance of the gastros- tomy}

Patient A was convinced before the operation and accepted placement of the gastrostomy. However, almost all of the subjects expressed negative acceptance preoperatively, saying "there's no other choice" and "it's unavoidable" but changed to positive acceptance after it was placed. Factors that appeared to be involved in the change are: (1) switches to more suitable types of gastrostomy tube for the level of physical function of the patients themselves, (2) improvement in trouble in the form of improvement of abnormal granulation or diarrhea, and (3) having come to the realization of the need for the gastrostomy. There are several types of gastrostomy, e.g., a bumper type, a balloon type, a button style and a catheter style. Thus, it is necessary to assess everyday living condi- tions and capacity for self care, which change with the progression of symptoms, and to assess the most appropriate type of gastrostomy tube together with the neurologist, surgeon (gastrointestinal surgery), nurses, patients themselves, and their family at the time the gastrostomy is created and every time it is replaced.

Moreover, from the standpoint of the safety of PEG, it is preferable to perform the procedure in ALS patients with enough respiratory function to tolerate PEG (\%FVC $\geq 50 \%$ ), even when oral feeding is possible. ${ }^{4}$ Thus, the content of the explanation must be adjusted, because patients do not yet realize the need for PEG. An effective explanation for positive acceptance may include the facts that the top priority is ensuring nutrition, that the sooner it is performed, the more a life-prolonging effect can be expected, that placement of an PEG does not mean that oral feeding is no longer possible, and that it is all right to continue oral feeding to the extent possible even after undergoing PEG.

\section{Care to prevent trouble}

Preventing trouble is also necessary in order to achieve positive acceptance of the gastrostomy. Diarrhea was cited as one of the causes of trouble while in the hospital, and the subject who experienced it had undergone gastric resection for stomach cancer. Care is required in regard to the concentration of the nutrient formula and the rate of infusion, taking into account the digestive capacity of each individual patient. The nutrition support teams (NSTs) in many hospitals are primarily active in the surgical area, but there are also reports that creation of gastrostomies and long-term care are common in the neurology field. ${ }^{3,10}$ 
It is hoped that there will be NST activity in the field of neurology and in communities. In other countries, the need for team care in the form of the multidisciplinary teams (MDTs) that include a nutritionist has been pointed out. ${ }^{3}$

Complaints and dissatisfaction related to trouble during replacement were identified in regard to being switched to a type of gastrostomy that was not wanted and being inserted an inappropriate size, as well as in regard to the replacement procedure itself. It is possible to maintain self care by switching to a different type of gastrostomy tube as the symptoms progress (e.g., a decrease in ability to hold the head up, in upper limb function, in finger function, etc). Moreover, because functions that ALS patients were able to perform are gradually lost as a result of the progression of the disease, it is absolutely necessary to avoid creating situations in which patients' degree of independence diminishes because of making a switch to another type against the patient's will. As there will be intervals of 3 months or 6 months between replacements, we must concern about the time of replacement. A system is needed in which examinations in the gastroenterology department are incorporated during regular clinical examinations in the neurology department.

There is a report of many accidents and complications occurring in association with the gastrostomy placement procedure. ${ }^{11,12}$ In addition to improvements in the procedure for creating the gastrostomy by physicians, taking into account ALS patients with reduced respiratory function, a medical practice system should be devised at the hospital so that patients are not made to wait for a very long time in the endoscopy room after being anesthetized.

It was also found that trouble occurred in patients' daily lives after actually returning home because pamphlets and necessary materials regarding the transition period to home care had not been provided by the hospital. A system is needed in which the materials and information required are always handed to the patient or to the attending physician of the community or visiting nurses at the time of discharge.

Many instances of trouble were also found to have occurred during home care, including skin trouble, leakage of the nutrient formula, and malfunctioning of equipment. In home environments without a permanent medical care provider, it is necessary for nurses who are closest to the patient and family to collect information through the family and members of other occupations. Nurses need to strive to provide their support in a support system that changes as the disease progresses, so that trouble is detected and responded to early. Even when improvement and maintenance of nutritional status have been achieved by PEG, it would be desirable if care could be provided in such a way that QOL were not diminished by suffering from trouble.

\section{Optimal approach to continuing care with the hospital and the community}

Sometimes a stoma is not used for a certain period of time after placement in ALS. In addition, there are times when education is difficult because the patient or family is in an unstable mental state due to the rapidity of the progression of the disease. In the view of continuing care, it is needed in which care is divided into care that must be performed daily (skin care with twisted tissues, etc.) and care that can be performed as little as once a week (flushing the tube with hot water, etc.). After attempting to educate the patient and family in regard to the care needed daily, the care system is maintained to entrust the specific nature of the care to the visiting nurses or clinic nurses in order to compensate for the insufficient part of the patient and family education.

\section{Conclusion}

1. In order to obtain positive acceptance of the gastrostomy, when the patient is still capable of oral feeding, it is necessary to modify the explanation so as to enable the patient to realize the need for the gastrostomy. Moreover, both education of the patient and the family and cooperation with the community are needed to avoid trouble after discharge from the hospital.

2. It is necessary for patients and professionals involved in patient care to consider selection of the most appropriate type of gastrostomy tube and site on the basis of an assessment of each individual's level of disease progression. It is needless to say to strengthen inter-occupational and intra-occupational coordination in hospitals by physicians and nurses as well as coordination in the community, in order to keep continuing care in regard to the placement of gastrostomies.

\section{Acknowledgement}

The authors wish to express our gratitude to all participants in this study for sharing their experiences with us. This study was supported by a Grant-in-Aid for Scientific Research (No.19592554) and the grant of NIHON KANGO KYOKAI SYUPPANKAI (Japanese Nursing Association Publishing Co.) in the fiscal year of 2008 .

\section{Conflict of interest}

Authors declare no conflict of interest. 


\section{References}

1. Miller RG, Jackson CE, England EJ. Practice Parameter update: The care of the patient with amyotrophic lateral sclerosis: Multidisciplinary care, symptom management, and cognitive/behavioral impairment (an evidence-based review). Neurology 2009; 73 : 1227-1233.

2. Hugel H, Grundy N, Rigby S, et. al. How does current care practice influence the experience of a new diagnosis of motor neuron disease? A qualitative study of current guidelines-based practice. Amyotrophic lateral sclerosis 2006; 7 : 161-166.

3. Rio A, Cawadias E. Nutritional advice and treatment by dietitians to patients with amyotrophic lateral sclerosis/ motor neurone disease: a survey of current practice in England, Wales, Northern Ireland and Canada. J Hum Nutr Diet 2007 ; 20 : 3-13.

4. Mazzini L, Corra T, Zaccala M, et al. Percutaneous endoscopic gastrostomy and enteral nutrition in amyotrophic lateral sclerosis. J Neurol 1995: 242: 695-698.

5. Desport JC, Preux PM, Truong TC et al. Nutritional status in a prognostic factor for survival in ALS patients. Neurology 1999; 53 : 1059-1063.

6. Andersen PM, Borasio GD, Dengler R, et al. Good Practice in the management of amyotrophic lateral sclerosis: clinical guidelines. An evidence-based review with good practice points. EALSC Working Group. Amyotrophic lateral sclerosis 2007 ; 8(4) : 195-213.

7. Mitsumoto H, DavidsonM, Moore D, et al. Percutaneous endoscopic gastrostomy (PEG) in patients with ALS and bulbar dysfunction. Amyotrophic Lateral Sclerosis and Other Motor Neuron Disorders 2003; 4(3) : 177-185.

8. Shimizu $\mathrm{T}$, Hayashi $\mathrm{H}$, Inoue $\mathrm{H}$, et al. Percutaneous endoscopic gastrostomy in amyotrophic lateral sclerosisrelation of respiratory function at the time of PEG to survival length [in Japanese]. Rinsyo Shinkeigaku 2008; 48(10) : 721-726.

9. Forbs RB, Colville S, Swingler RJ. Frequency, timing and outcome of gastrostomy tubes for amyotrophic lateral sclerosis/motor neuron disease- a record linkage study form the Scottish Motor Neurone Disease Register 2004; 251(7): 813-817.

10. Shimizu T, Hanaoka T, Hayashi H, et al. : Percutaneous endoscopic gastrostomy in patients with intractable neurological diseases-retrospective study of the indication, complication and prognosis [in Japanese]. Rinsho Shinkeigaku 2007 ; 47 : 565-570.

11. Nozaki S, Ando N, Komuta R, et al.: The actual conditions about placement and management of PEG in the neurological ward of National hospital organization (in Japanese: Kokuritsu Byouin KikouNo Shinkeinaikabyoutou Niokeru PEG zousetsu to Kanri No Genjyo) IRYO 2007; $61:$ 484-489.

12. Nozaki S, Ando N, Komuta R, et al.: Reexamination on the safety and management of PEG among chronic neuromuscular diseases-PEG from the viewpoint of patients (in Japanese: Mansei ShinkeikinShikkann Niokeru PEG no Anzensei toKanri ni tsuiteno Saikentou -Kanjya kara mita PEG-) IRYO 2007; $61:$ 205-210. 